\title{
Short Communication: \\ Landscape composition alters parasitoid wasps but not their host diversity in tropical agricultural landscapes
}

\author{
TAZKIYATUL SYAHIDAH ${ }^{1}$, AKHMAD RIZALI ${ }^{2, \bullet}$, LILIK B. PRASETYO ${ }^{3}$, PUDJIANTO $^{4}$, \\ DAMAYANTI BUCHORI ${ }^{4}$ \\ ${ }^{1}$ Doctoral Program in Plant Pests and Diseases, Graduate School, Institut Pertanian Bogor. Jl. Kamper, Dramaga, Bogor 16680, West Java, Indonesia \\ ${ }^{2}$ Department of Plant Pest and Diseases, Faculty of Agriculture, Universitas Brawijaya. J1. Veteran, Malang 65145, East Java, Indonesia. \\ Tel/fax.: +62-341-575843. `email: arizali@ub.ac.id, tazkiyasyahidah@gmail.com \\ ${ }^{3}$ Department of Resource Conservation and Ecotourism, Faculty of Forestry, Institut Pertanian Bogor. Jl. Lingkar Akademik, Dramaga, Bogor 16680, \\ West Java, Indonesia. \\ ${ }^{4}$ Department of Plant Protection, Faculty of Agriculture, Institut Pertanian Bogor. Jl. Meranti, Dramaga, Bogor 16680, West Java, Indonesia
}

Manuscript received: 27 October 2019. Revision accepted: 28 March 2020.

\begin{abstract}
Syahidah T, Rizali A, Prasetyo LB, Pudjianto, Buchori D. 2020. Short Communication: Landscape composition alters parasitoid wasps but not their host diversity in tropical agricultural landscapes. Biodiversitas 21: 1702-1706. The diversity of parasitoid wasps and their hosts in an agricultural landscape is affected by crop management and habitat conditions around crop fields. The composition of agricultural landscapes that are dominated by non-crop or natural habitats are assumed to be able to support the presence of parasitoid wasps as biological control of pests. The aim of this study was to investigate the effect of landscape composition on the diversity of parasitoid wasps and their hosts in agricultural landscapes. The research observations were conducted on six fields of long-bean cultivation located in Bogor District, West Java Province, Indonesia. Parasitoid wasps were collected by hand-collecting of their hosts (lepidopteran larvae) within $60 \mathrm{~m}$ distance transect to each long-bean field. In total, 17 species of parasitoid wasps and 12 species of lepidopteran larvae were found from all agricultural landscapes. A parasitoid wasp, Microplitis manilae was found in all longbean fields (except Bantarjaya) and only parasitized the tobacco cutworm (Spodoptera litura). The tomato looper, Chrysodeixis chalcites had the highest associated parasitoids and was also parasitized by Braconidae sp5 which was also a parasitoid of $S$. litura. Based on the analysis results, the patch numbers of natural habitats had a positive effect on the diversity of parasitoid wasps and had no effect on the diversity of lepidopteran larvae. In conclusion, landscape compositions with patchy natural habitats have an important role to preserve beneficial insects and maintain ecosystem services in tropical agricultural landscapes.
\end{abstract}

Keywords: Beneficial insect, Bogor, lepidopteran larvae, long-bean, natural habitat

\section{INTRODUCTION}

Understanding the factors affecting hymenopteran parasitoid communities is pivotal for conservation efforts in agroecosystem. Research by Tylianakis et al. (2007) reveals that the structure of host-parasitoid food-web is altered by habitat modification, for which parasitism rates increased in modified habitats. Agricultural landscapes with more extensive and diversified non-crop habitats also influence host densities, parasitism rates, and species richness of parasitoids and hyperparasitoids (Plećaš et al. 2014). In addition, agricultural intensification, especially through insecticide application (Desneux et al. 2007) and high intensity farming practices (Lohaus et al. 2013), has a negative effect on parasitoid communities. Those factors are simultaneously considered for agricultural management not only at site scale (such as by cultural practices) but also at landscape scale.

However, several studies have shown contrary evidence on the effects of habitat modification and agricultural intensification on parasitoid diversity and their potential for biological control at both site and landscape scales. A study by Jonsson et al. (2012) reveals that a higher intensity of farming system at a site scale can be a more important driver in host-parasitoid interactions than habitat diversity. Crop habitats might also provide more important resources for parasitoids than non-crop or natural habitats (Sann et al. 2018). At landscape scale, a study by Ulina et al. (2019) showed that the patch number of croplands can influence parasitoid diversity and suggested that the management of agricultural landscapes needs not only to preserve non-crop habitat, but also to increase the patch number of croplands. Therefore, studies on the relationship between landscape composition, either patches of crops or non-crops, and parasitoid communities are still needed in order to enrich existing knowledge to understand and develop management strategies to achieve sustainable agriculture.

The relationship between the composition of agricultural landscapes and hymenopteran parasitoids in cropland has been studied. According to Fahrig et al. (2011), landscape composition is related to the number and proportions of different habitat types in a landscape. A landscape composition with more extensive and diversified non-crop habitats can enhance parasitoid wasp diversity, 
which offers pest control services in an agroecosystem (Balzan et al. 2016). The composition of an agricultural landscape is also reflected by landscape complexity. A simple landscape may be disadvantageous to parasitoid wasps that require alternative hosts, shelter, and alternative sources of pollen and nectar (Gagic et al. 2011). In contrast, a complex landscape can increase parasitoid diversity and biological pest control because of the high proportion of non-crop or natural habitats in such landscape (Wratten et al. 2012). However, landscape complexity is not a major trigger of species richness and the food web structure of parasitoids (Hawro et al. 2015). The effect of landscape complexity on biological control may vary in different geographical areas (Thies et al. 2011). Although non-crop habitats may support parasitoids diversity in croplands (Plećaš et al. 2014), their existence does not consistently improve biological control of pest in agroecosystems (Karp et al. 2018).

In this study, we examined the influence of agricultural landscape composition on the diversity of parasitoid wasps, and indirectly, on the diversity of their host (lepidopteran larvae) in long-bean fields. We measured landscape composition i.e. the proportion of croplands and seminatural habitats and then associated with the diversity and abundance of parasitoid wasps and lepidopteran larvae. We hypothesized that the high proportion of semi-natural habitats increases the diversity of parasitoid wasps in agricultural landscapes.

\section{MATERIALS AND METHODS}

\section{Study area and landscape characterization}

This research was conducted in agricultural landscapes located in six villages in Bogor District, West Java, Indonesia (Figure 1). The characteristics of agricultural landscapes in Bogor consist of patchy croplands and the presence of semi-natural habitats (Ulina et al. 2019). In each village, a crop field was selected with the distance between crop fields in other villages being at least $2 \mathrm{~km}$ apart in order to avoid overlapping landscapes and spatial autocorrelation (Tischendorf and Fahrig 2000). Each crop field was planted with long-bean plants using traditional techniques applied by local farmers.

The characterization of agricultural landscape was carried out by establishing circle with a radius of $500 \mathrm{~m}$ from the center of the long-bean field (approximately 78.5 ha). The radius was based on Klein et al. (2006) as the appropriate scale for studying insect communities, especially parasitoid wasps, in tropical regions. Land uses around long-bean fields were manually digitized using QGIS software (QGIS Development Team 2016) and classified into five categories of croplands, semi-natural habitats, settlements, roads, and water bodies. The FRAGSTAT software (McGarigal et al. 2012) was utilized to calculate landscape parameters including the number of patches (NP) and the class area (CA) both semi-natural habitats and croplands.

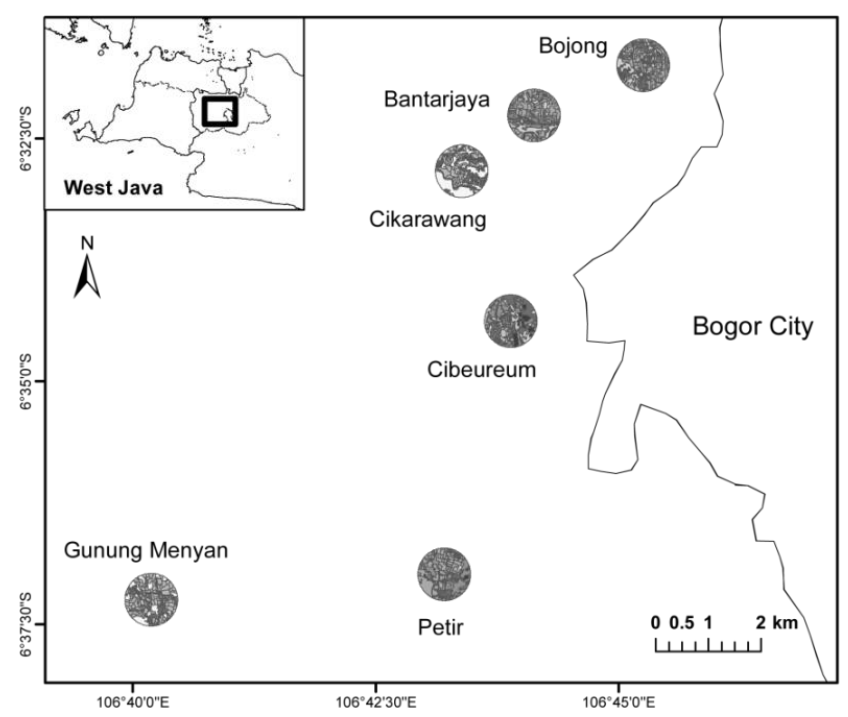

Figure 1. Map of study area of agricultural landscapes located in six villages in Bogor District, West Java, Indonesia

\section{Sampling method of insects}

To collect parasitoid wasps in long-bean field, we sampled their hosts (lepidopteran larvae) using handpicking method. Samplings were conducted from July to September 2016 at both the vegetative stage ( 2 and 3 weeks after planting) and the generative stage (5, 6 and 7 weeks after planting) of long-bean plants. Lepidopteran larvae were collected within a $60 \mathrm{~m}$ distance of a transect line or approximately 200 plants per long-bean field. The collected lepidopteran larvae were then placed individually into a labeled plastic vial containing long-bean leaves and brought to laboratory to be reared.

Lepidopteran larvae were observed daily to record their development stages, parasitoid or moth emergence and also feeding larvae. The parasitized larvae were separated and intensively observed until adult parasitoids emerged. All adult parasitoid wasps were identified to the family level based on their morphological characteristics using available references (e.g. Goulet and Huber 1993; Gibson et al. 1997; Wharton et al. 1997). Identification to morphospecies level was based on morphological characteristics compared to voucher specimens at the entomology laboratory, Museum Zoologicum Bogoriense, Indonesian Institute of Sciences (LIPI), Bogor, Indonesia.

\section{Data analysis}

The effects of landscape composition on parasitoid wasps and lepidopteran larvae were analyzed by fitting a generalized linear model (GLM) without interactions (Zuur et al. 2009) and using a quasipoisson distribution to account for overdispersion. Explanatory variables included class area (CA.nat) and patch number (NP.nat) of seminatural habitats, class area (CA.crop) and patch number (NP.crop) of croplands, and species richness of lepidopteran larvae/hymenopteran parasitoids. The GLM analysis was performed using $\mathrm{R}$ statistics software (R Core Team 2019). 


\section{RESULTS AND DISCUSSION}

\section{Diversity of parasitoid wasps and lepidopteran larvae from long-bean field in different agricultural landscape}

In total, we found 17 species of parasitoid wasps and 12 species of lepidopteran larvae from long-bean fields in six agricultural landscapes in Bogor (Table 1). The highest species richness of parasitoid wasps was found in Gunung Menyan (12 species) with the highest patch number of natural habitats (26 patches). The highest richness of lepidopteran species was recorded in Cikarawang (10 species) with the lowest patch number of natural habitats (16 patches). Surprisingly, we did not find parasitoids from the Bantarjaya landscape, although the abundance of lepidopteran larvae was higher than Cibeureum and Petir.
The presence of natural habitats seems to have an effect on the diversity of parasitoid wasps and lepidopteran larvae. This finding is similar to the research hypothesis which is that the proportion of natural habitats affects the presence of parasitoid wasps in an agricultural landscape. The presence of natural habitats has important contributions for natural enemies (Tscharntke et al. 2016), especially to support shelter, alternative hosts, and alternative sources of pollen and nectar (Gagic et al. 2011). However, a previous study with cucumber field in Bogor showed a different pattern in that landscape with higher proportions of natural habitats did not influence the abundance of parasitoid wasps and herbivorous insects (Ulina et al. 2019).

Table 1. Landscape composition (NP.nat=patch number of natural habitats, CA.nat=area of natural habitats (ha), NP.crop=patch number of crop fields, CA.crop=area of crop fields (ha)) and species diversity ( $\mathrm{S}=$ species richness, $\mathrm{N}=$ number of individuals) of parasitoid wasps and lepidopteran larvae collected from long-bean fields from different agricultural landscapes in Bogor, Indonesia

\begin{tabular}{|c|c|c|c|c|c|c|c|c|}
\hline \multirow{2}{*}{ Landscape } & \multicolumn{2}{|c|}{ Natural habitat } & \multicolumn{2}{|c|}{ Crop field } & \multicolumn{2}{|c|}{ Parasitoid } & \multicolumn{2}{|c|}{ Lepidopteran } \\
\hline & NP.nat & CA.nat & NP.crop & CA.crop & $\mathbf{S}$ & $\mathbf{N}$ & $\mathbf{S}$ & $\mathbf{N}$ \\
\hline Bantarjaya & 19 & 19.50 & 76 & 36.05 & 0 & 0 & 8 & 411 \\
\hline Bojong & 22 & 17.20 & 118 & 44.08 & 2 & 57 & 9 & 476 \\
\hline Cibeureum & 22 & 20.00 & 70 & 26.07 & 6 & 23 & 8 & 233 \\
\hline Cikarawang & 16 & 36.41 & 82 & 27.11 & 4 & 13 & 10 & 427 \\
\hline Gunung Menyan & 26 & 20.84 & 95 & 41.38 & 12 & 33 & 9 & 491 \\
\hline Petir & 25 & 22.69 & 79 & 44.15 & 3 & 6 & 9 & 329 \\
\hline Total & & & & & 17 & 132 & 12 & 2367 \\
\hline
\end{tabular}

Table 2. Diversity of lepidopteran larvae and parasitoid wasps collected from six long-bean fields in different agricultural landscapes in Bogor, Indonesia

\begin{tabular}{|c|c|c|c|}
\hline Lepidopteran larvae & Presence & Parasitoid & Presence \\
\hline \multirow[t]{5}{*}{ Chrysodeixis chalcites } & all & Ceraphronidae $\mathrm{sp} 1$ & ck \\
\hline & & Braconidae sp4 & $\mathrm{cb}, \mathrm{gm} \& \mathrm{pr}$ \\
\hline & & Braconidae sp5 & $\mathrm{gm}$ \\
\hline & & Braconidae $\mathrm{sp} 8$ & $\mathrm{gm}$ \\
\hline & & Eulophidae sp2 & $\mathrm{ck} \& \mathrm{gm}$ \\
\hline Crambidae sp2 & all & not parasitized & \\
\hline Geometridae sp1 & all & not parasitized & \\
\hline Hesperiidae sp1 & all & not parasitized & \\
\hline Limacodidae sp1 & bo \& gm & not parasitized & \\
\hline \multirow[t]{3}{*}{ Lymantriidae sp1 } & all & Elasmidae sp1 & $\mathrm{ck}$ \\
\hline & & Eulophidae sp1 & $\mathrm{gm}$ \\
\hline & & Eulophidae sp2 & $\mathrm{ck}$ \\
\hline Lymantriidae $\mathrm{sp} 2$ & bj \& pr & not parasitized & \\
\hline Maruca vitrata & all & Therobillus marucae & $\mathrm{cb} \& \mathrm{gm}$ \\
\hline Sesiidae sp1 & $\mathrm{ck}$ & not parasitized & \\
\hline \multirow{8}{*}{ Sphingidae sp1 } & all & Encyrtidae sp1 & $\mathrm{gm}$ \\
\hline & & Encyrtidae sp3 & $\mathrm{cb}$ \\
\hline & & Encyrtidae sp4 & $\mathrm{cb}$ \\
\hline & & Encyrtidae sp5 & $\mathrm{cb}$ \\
\hline & & Scelionidae sp1 & $\mathrm{gm}$ \\
\hline & & Trichogrammatidae sp1 & $\mathrm{gm}$ \\
\hline & & Trichogrammatidae sp2 & $\mathrm{gm}$ \\
\hline & & Trichogrammatidae sp3 & bo \& gm \\
\hline \multirow[t]{2}{*}{ Spodoptera litura } & bo, cb, ck, gm \& pr & Braconidae sp5 & $\mathrm{pr}$ \\
\hline & & Microplitis manilae & bo, cb, ck, gm \& pr \\
\hline Tortricidae $\mathrm{sp} 1$ & ck & not parasitized & \\
\hline
\end{tabular}

Note: Code of agricultural landscapes: bj: Bantarjaya, bo: Bojong, cb: Cibeureum, ck: Cikarawang, gm: Gunung Menyan, pr: Petir 


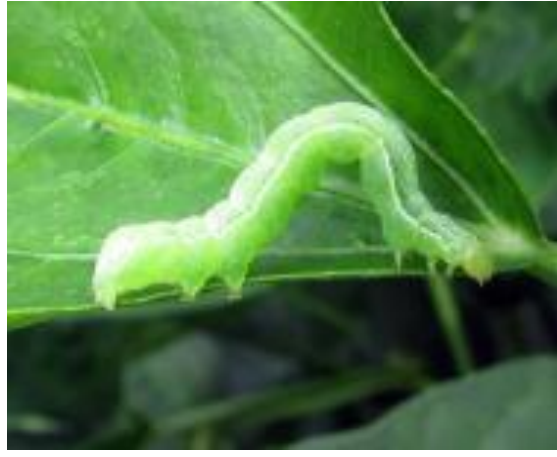

A

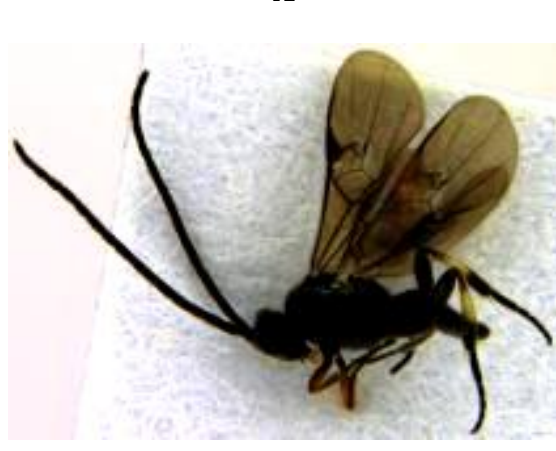

C
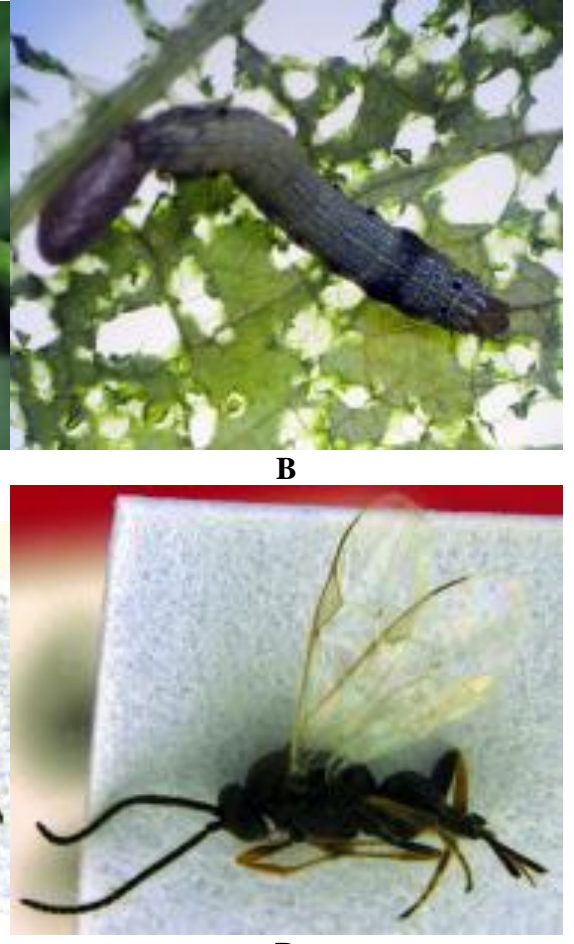

D

Figure 2. Common lepidopteran larvae: A. Chrysodeixis chalcites and B. Spodoptera litura recorded in long-bean fields and their parasitoid species: C. Microplitis manilae and D. Braconidae sp5.

Table 3. Generalized linear models relating the diversity of parasitoid wasps and lepidopteran larvae to the diversity of lepidopteran larvae (S.lep)/parasitoid wasps (S.par), patch number (NP.nat) and class area (CA.nat) of natural habitats, patch number (NP.crop) and class area (CA.crop) of croplands as predictors

\begin{tabular}{lcccccc}
\hline \multirow{2}{*}{ Variable } & \multicolumn{3}{c}{ Parasitoid wasp } & \multicolumn{3}{c}{ Lepidopteran larvae } \\
\cline { 2 - 7 } & Estimate & SE & P & Estimate & SE & P \\
\hline (Intercept) & -9.151 & 4.18 & 0.035 & 0.472 & 0.60 & 0.437 \\
S.lep & 0.338 & 0.15 & 0.033 & & & \\
S.par & & & & 0.038 & 0.02 & 0.082 \\
$\quad$ NP.nat & 0.406 & 0.15 & 0.011 & 0.012 & 0.02 & 0.595 \\
CA.nat & 0.053 & 0.06 & 0.406 & 0.013 & 0.01 & 0.167 \\
NP.crop & 0.038 & 0.03 & 0.213 & 0.004 & 0.00 & 0.276 \\
CA.crop & -0.181 & 0.07 & 0.018 & 0.009 & 0.01 & 0.437 \\
\hline
\end{tabular}

From 12 species of lepidopteran larvae, only 5 species were found to be parasitized by parasitoid wasps (Table 2). The tomato looper, Chrysodeixis chalcites (Lepidoptera: Noctuidae) (Figure 2.A) and Sphingidae sp1 have the highest associated parasitoids and were always found in all study areas. According to Alami et al. (2014), C. chalcites is one of the most important polyphagous insect pests of vegetables, ornamentals and greenhouse plants that has distribution in Africa, Oceania, Southern Europe, and South Asia. In addition, the tobacco cutworm, Spodoptera litura (Lepidoptera: Noctuidae) (Figure 2.B) was also found in all study areas (except Bantarjaya) and always parasitized with Microplitis manilae (Hymenoptera: Braconidae) (Figure 2.C). S. litura is reported as generalist herbivores and important pests in many agricultural cropping systems which have been recognized in 389 species of host plants (Qing et al. 2006). As a solitary endoparasitoid and the most common parasitoid of $S$. litura, M. manilae is not native to Indonesia, as it originated from China (Rao et al. 1993). Another braconid parasitoid, Braconidae sp5 (Figure 2.D) was found to parasitize $C$. chalcites and $S$. litura but in different longbean fields.

\section{Effect of landscape composition on parasitoid wasps and their host diversity}

The GLM analysis showed that landscape composition, especially patch numbers of natural habitats and species richness of lepidopteran larvae had a positive effect on the diversity of parasitoid wasps $(\mathrm{P}=0.011)$ and had no effect on lepidopteran larvae (Table 3). Class area of croplands also had a negative effect on the diversity of parasitoid wasps $(\mathrm{P}=0.018)$. In addition, the diversity of parasitoid wasps is affected not only by landscape composition but also by their host diversity $(\mathrm{P}=0.033)$.

Similar to the research hypothesis, the proportion of natural habitats affected parasitoid diversity in long-bean fields. In Bogor, the agricultural landscapes are mostly characterized by patchy semi-natural habitats that can maintain natural enemies especially parasitoids. Natural habitats or non-crop habitats can enhance parasitoid wasps and offer pest control services in an agroecosystem (Balzan et al. 2016). The availability of alternative hosts and alternative sources may have contributed to the positive 
effects of natural habitats on parasitoid wasps (Menalled et al. 1999; Brewer and Elliott 2004). However, the diversity of parasitoid wasps is also related to the diversity of lepidopteran larvae for which their diversity had no relationship with natural habitats.

Our findings suggest that management of agricultural landscapes needs to preserve semi-natural habitats and increase patch number of semi-natural habitats. This approach is appropriate to the conservation planning dilemma in that single large natural habitats or several small patchy natural habitats (Diamond 1975) seem more effective for preserving parasitoids in agricultural landscapes. In the case of the long-bean plant, planting in tropical agricultural landscapes with patchy semi-natural habitats provides benefits for beneficial insects especially parasitoid wasps and maintains ecosystem services by controlling pest populations under the economic threshold.

\section{ACKNOWLEDGEMENTS}

Gratitude is due to the six long-bean farmers in Bogor for providing access to their fields for this study. Gratitude is also due to the PMDSU (Master and Doctorate Programs for Leading Scholars), the DIKTI and the Bogor Agricultural Institute for supporting part of the research funding as well as all Entomology colleagues who supported this research.

\section{REFERENCES}

Alami S, Naseri B, Golizadeh A, Razmjou J. 2014. Age-stage, two-sex life table of the tomato looper, Chrysodeixis chalcites (Lepidoptera: Noctuidae), on different bean cultivars. Arthropod-Plant Interact 8: 475-484.

Balzan MV, Bocci G, Moonen AC. 2016. Landscape complexity and field margin vegetation diversity enhance natural enemies and reduce herbivory by Lepidoptera pests on tomato crop. BioControl 61: 141154.

Brewer MJ, Elliott NC. 2004. Biological control of cereal aphids in North America and mediating effects of host plant and habitat manipulations. Ann Rev Entomol 49: 219-242.

Desneux N, Decourtye A, Delpuech J-M. 2007. The sublethal effects of pesticides on beneficial arthropods. Ann Rev Entomol 52: 81-106.

Diamond JM. 1975. The island dilemma: lessons of modern biogeographic studies for the design of natural reserves. Biol Conserv 7: 129-146.

Fahrig L, Baudry J, Brotons L, Burel FG, Crist TO, Fuller RJ, Sirami C, Siriwardena GM, Martin J-L. 2011. Functional landscape heterogeneity and animal biodiversity in agricultural landscapes. Ecol Lett 14: 101-112.

Gagic V, Tscharntke T, Dormann CF, Gruber B, Wilstermann A, Thies C. 2011. Food web structure and biocontrol in a four-trophic level system across a landscape complexity gradient. Proc R Soc B: Biol Sci 278: 2946-2953.

Gibson GAP, Huber JT, Woolley JB. 1997. Annotated Keys to the Genera of Nearctic Chalcidoidea (Hymenoptera), NRC Research Press, Ottawa.

Goulet H, Huber JT. 1993. Hymenoptera of the World: An Identification Guide to Families. Canada Communication Group Publishing, Ottawa.

Hawro V, Ceryngier P, Tscharntke T, Thies C, Gagic V, Bengtsson J, Bommarco R, Winqvist C, Weisser WW, Clement LW, Japoshvili G,
Ulrich W. 2015. Landscape complexity is not a major trigger of species richness and food web structure of European cereal aphid parasitoids. BioControl 60: 451-461.

Jonsson M, Buckley HL, Case BS, Wratten SD, Hale RJ, Didham RK. 2012. Agricultural intensification drives landscape-context effects on host-parasitoid interactions in agroecosystems. J Appl Ecol 49: 706714.

Karp DS, Chaplin-Kramer R, Meehan TD, Martin EA, DeClerck F, et al 2018. Crop pests and predators exhibit inconsistent responses to surrounding landscape composition. Proc Natl Acad Sci USA 115: E7863-E7870.

Klein AM, Steffan-Dewenter I, Tscharntke T. 2006. Rain forest promotes trophic interactions and diversity of trap-nesting Hymenoptera in adjacent agroforestry. J Anim Ecol 75: 315-23.

Lohaus K, Vidal S, Theis C. 2013. Farming practices change food web structures in cereal aphid-parasitoid-hyperparasitoid communities. Oecologia 171: 249-259.

McGarigal K, Cushman SA, Ene E. 2012. FRAGSTATS v4: Spatial Pattern Analysis Program for Categorical and Continuous Map. University of Massachusetts, Amherst, MS.

Menalled FD, Marino PC, Gage SH, Landis DA. 1999. Does agricultural landscape structure affect parasitism and parasitoid diversity? Ecol Appl 9: 634-641.

Plećaš M, Gagic V, Jankovic M, Petrovic-Obradovic O, Kavallieratos NG, Tomanovic Z, Thies C, Tscharntke T, Cetkovic A. 2014. Landscape composition and configuration influence cereal aphid-parasitoidhyperparasitoid interactions and biological control differentially across years. Agric Ecosyst Environ 183: 1-10.

QGIS Development Team. 2016. QGIS Geographic Information System. Open Source Geospatial Foundation Project,

Qing HG, Wang DD, Ding J, Huang RH, Ye ZX. 2006. Host plants of Spodoptera litura. Acta Agric Jiangxi 18: 51-59.

R Core Team. 2019. R: A Language and Environment for Statistical Computing. R Foundation for Statistical Computing, Vienna, Austria.

Rao GVR, Wightman JA, Rao DVR. 1993. World review of the natural enemies and diseases of Spodoptera litura (F.) (Lepidoptera: Noctuidae). Intl J Trop Insect Sci 14: 273-284.

Sann C, Theodorou P, Heong KL, Villareal S, Settele J, Vidal S, Westphal C. 2018. Hopper parasitoids do not significantly benefit from noncrop habitats in rice production landscapes. Agric Ecosyst Environ 254: 224-232.

Thies C, Haenke S, Scherber C, Bengtsson J, Bommarco R, Clement LW, Ceryngier P, Dennis C, Emmerson M, Gagic V, Hawro V, Liira J, Weisser WW, Winqvist C, Tscharntke T. 2011. The relationship between agricultural intensification and biological control: experimental tests across Europe. Ecol Appl 21: 2187-2196.

Tischendorf L, Fahrig L. 2000. On the usage and measurement of landscape connectivity. Oikos 90: 7-19.

Tscharntke T, Karp DS, Chaplin-Kramer R, Batáry P, DeClerck F, Gratton C, Hunt L, Ives A, Jonsson M, Larsen A, Martin EA, Martínez-Salinas A, Meehan TD, O'Rourke M, Poveda K, Rosenheim JA, Rusch A, Schellhorn N, Wanger TC, Wratten S, Zhang W. 2016. When natural habitat fails to enhance biological pest control-Five hypotheses. Biol Conserv 204: 449-458.

Tylianakis JM, Tscharntke T, Lewis OT. 2007. Habitat modification alters the structure of tropical host-parasitoid food webs. Nature 445: 202205.

Ulina ES, Rizali A, Manuwoto S, Pudjianto, Buchori D. 2019. Does composition of tropical agricultural landscape affect parasitoid diversity and their host-parasitoid interactions? Agric For Entomol 21: 318-325.

Wharton RA, Marsh PM, Sharkey MJ. 1997. Manual of the New World Genera of the Family Braconidae (Hymenoptera), International Society of Hymenopterists, Washington DC.

Wratten SD, Gillespie M, Decourtye A, Mader E, Desneux N. 2012. Pollinator habitat enhancement: benefits to other ecosystem services. Agric Ecosyst Environ 159: 112-122.

Zuur AF, Ieno EN, Walker NJ, Saveliev AA, Smith GM. 2009. Mixed Effects Models and Extensions in Ecology with R, Springer, New York 